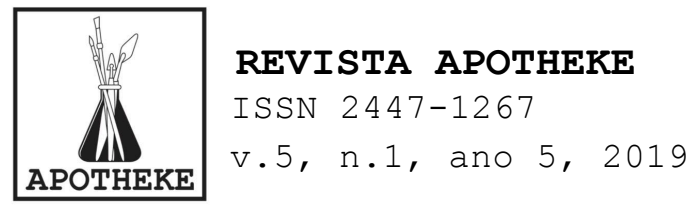

\title{
Perguntas, anotações [sob exercícios de escrita e escuta]
}

\author{
Maria Raquel da Silva Stolf (UDESC)
}

\begin{abstract}
RESUMO: O presente texto foi escrito sob o efeito de propostas de exercícios de escrita e escuta, e a partir da reverberação de apontamentos e reflexões ocorridas durante e após a oficina Laboratório Imersivo Projeto TUBO DE ENSAIO, por mim conduzida em parceria com Andrea Bardawil, no SESC-Cacupé, em Florianópolis, em 2015. A oficina integrou as atividades do Projeto TUBO DE ENSAIO - Composição [Interseções + Intervenções], coordenado por Sandra Meyer, Jussara Xavier e Vera Torres. Deste modo, este texto desdobra reflexões de um texto homônimo, publicado no livro Tubo de ensaio: composição [Interseções + Intervenções] (2016), investigando algumas de suas perguntas e indicando outras reverberações de experiências, as quais atravessam meus processos enquanto artista, professora e pesquisadora. As anotações propõem diálogos com George Brecht, Yoko Ono, John Cage, Jorge Larrosa, Thierry Davila, Maurice Blanchot, David Le Breton, entre outros autores.
\end{abstract}

PALAVRAS-CHAVE: Experiência; Processo de escrita; Escuta de processo; Silêncio.

RESUMEN: El presente texto fue escrito bajo el efecto de propuestas de ejercicios de escritura y escucha, y a partir de la reverberación de apuntes y reflexiones ocurridas durante y después del taller Laboratório Imersivo - Projeto TUBO DE ENSAIO, por mí conducido con Andrea Bardawil, en Florianópolis, en SESC-Cacupé, en 2015. El taller integró las actividades del Projeto TUBO DE ENSAIO - Composição [Interseções + Intervenções], coordinado por Sandra Meyer, Jussara Xavier y Vera Torres. De este modo, este texto desdobla reflexiones de un texto homónimo, publicado en el libro Tubo de ensaio: composição [Interseções + Intervenções] (2016), investigando algunas de sus preguntas e indicando otras reverberaciones de experiencias, las cuales intersectan mis procesos como artista, profesora e investigadora. Las anotaciones proponen diálogos con George Brecht, Yoko Ono, John Cage, Jorge Larrosa, Thierry Davila, Maurice Blanchot, David Le Breton, y otros autores.

PALABRAS CLAVE: Experiencia; Proceso de escritura; Escucha de proceso; Silencio.

\section{$08 \mathrm{~h} 55$}

Como pensar a relação entre processo, composição e decomposição, entre imersão e emersão? Poderia começar a atravessar essa pergunta pressupondo a indefinição (de contornol de uma experiência, o tempo que algo leva para acontecer, para decantar e para ser registrado (na página e/ou no corpo).

\section{$17 \mathrm{~h} 37$}




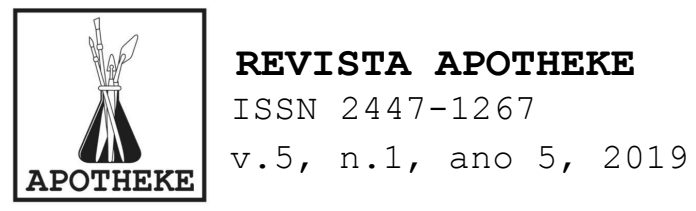

Uma experiência pode desencadear uma ação, a partir de um registro? E essa ação, por sua vez, pode catalisar outra experiência e um acontecimento? Que linguagem a experiência solicita, ou que registros possibilitam tentar fisga-la? Como anota Larrosa (2014) "necessitamos de uma linguagem para a experiência", que não pode ser antecipada, pois

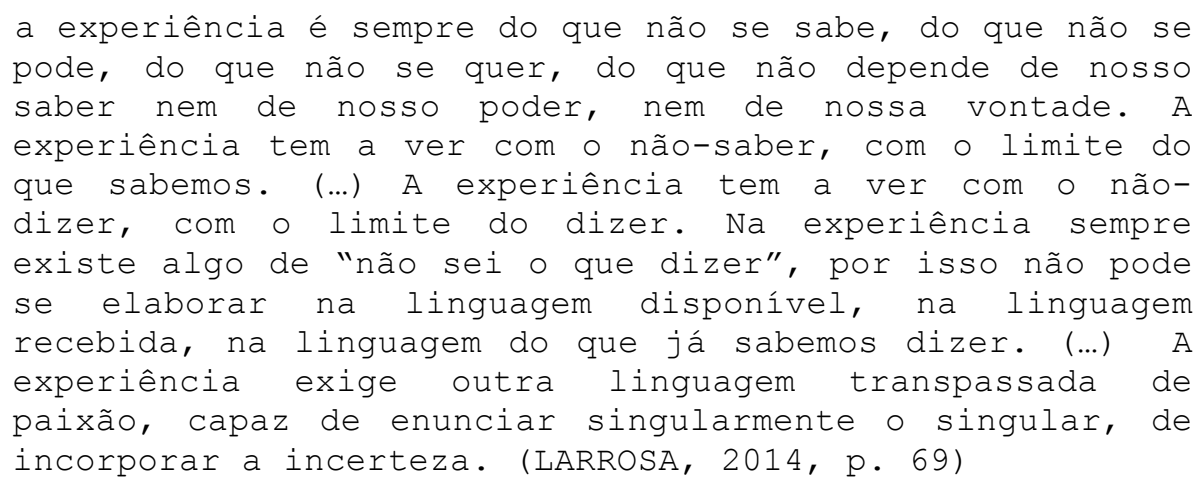

\section{$23 \mathrm{~h} 00$}

O tempo que leva para compor/decompor um acontecimento (o que se passou em nós ou nos atravessou), que por sua vez pode concatenar um processo e deslizar (n) um começo.

\section{$19 h 04$}

Tentar incorporar a incerteza ou essa travessia invisível (de si e para fora/dentro de si) envolve um tempo alongado, dilatado, um tempo ao/de revés. Envolve tentar escutar o trânsito que ocorre nesse espaçamento, no espaço exterior da escrita e na margem de sentido da escuta. Jean-Luc Nancy (2014) assinala que estar à escuta implica em estar inclinado, pendente numa borda, como se o próprio som fosse essa margem suspensa. Na beira de escuta (de um processo), a escrita pode ser a isca ou uma pista?

\section{$23 h 10$}

Uma palavra pode catalisar um acontecimento? 


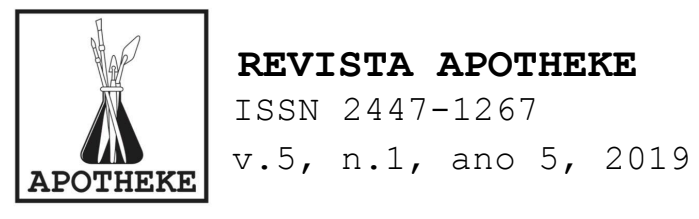

\section{$23 h 33$}

George Brecht, que integrou o grupo fluxus e participou dos cursos de John Cage (entre 1958 e 1959, na New School for Social Research em Nova Iorque), propôs o conceito de evento e elaborou proposições escritas, impressas em pequenos cartões, denominadas "event-scores" ("partituras-de-evento"). Brecht sublinha que a "partitura é um evento; assim como achar uma incidência de sua existência" (BRECHT, 2002, p. 84), sendo que se

ao compor música, o compositor proporciona uma
experiência organizando uma situação dentro da qual sons
são criados [e se] uma partitura musical (partitura de
som) proporciona uma situação sonora musical, a
partitura-evento proporciona uma situação para eventos
em todas as dimensões (ou fora delas). (...) [Deste
modo, as] partituras-de-evento preparam para eventos que
acontecem no 'agora' de cada um. (BRECHT, 2002, p. 84)

Em 1963, o artista publicou Water Yam, com setenta e três cartões contendo "partituras-evento", entre eles, um cartão intitulado EGG que traz a indicação: "at least one egg", algo como "ao menos um ovo". Já em AIR CONDITIONING, há a instrução: "( move through the place )", ou seja, "mova-se pelo lugar". ${ }^{1}$ Em Word Event (1961), um pequeno cartão apresenta apenas seu título e a palavra "Exit" ("saída"), entre aspas, como notação. O artista executa algumas versões dessa "partitura-evento", entre as quais sua realização como uma placa com a palavra "Exit", a qual ele instala sobre a porta de entrada de sua casa, documentando-se fotograficamente a ocorrência da partitura. "Exit" indica a possibilidade de uma palavra constituir-se enquanto acontecimento e notação em/de um espaço - as saídas diárias de Brecht de casa seriam espécies de ações artísticas silenciosas?

\footnotetext{
1 Disponível em http://www.artnotart.com/fluxus/gbrecht-wateryam.html. Acesso em 10/05/2007.
} 


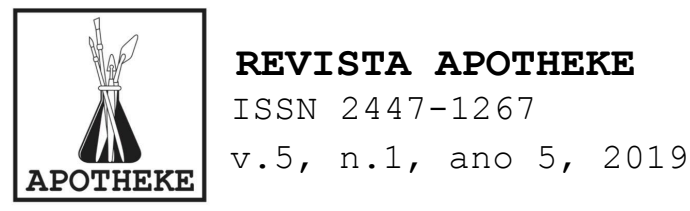

Dominique Bosseur e Jean-Yves Bosseur (1990) sublinham que suas "partituras-evento"

constituem

" 'exercícios multissensoriais para o ouvinte/espectador', onde são constantemente pesquisados pontos de intersecção precisos com a realidade." (BOSSEUR, 1990, p. 164). Pressupõe-se aqui a conjunção arte-vida, ou como o próprio Brecht pergunta: "Se a arte não for forma, pode ser (vida) ao invés de arte. / ou: Pode a arte não ter forma e ainda ser arte?" (2002, p. 84)

\section{$23 h 48$}

Sair e/ou entrar passa pela linguagem?

\section{$23 \mathrm{~h} 50$}

A duração de um processo: como um projeto e um gesto começam a pulsar? Como um redemoinho se forma e se propaga? Por/para onde ele se forma? Como ele dura em nós, entre nós e para dentro/para fora de nossas contingências?

\section{$23 h 55$}

Uma palavra pode catalisar uma situação corporal e/ou vice-versa?

\section{3h59}

No livro-projeto intitulado Fidget, Kenneth Goldsmith falou, gravou e transcreveu os movimentos de seu corpo durante 13 horas de um dia de 1997 (16 de junho - dia do Bloomsday). Goldsmith anexou um microfone ao corpo e narrou todo movimento corporal que observou entre 10h00 (quando acordou) e 23h00 (quando foi dormir). Assinala ainda que foi impossível descrever todos os seus movimentos, sendo que o que importava era o movimento de "um corpo no espaço", e não de seu corpo num espaço. E, ao transcrever tudo o que conseguiu narrar, 


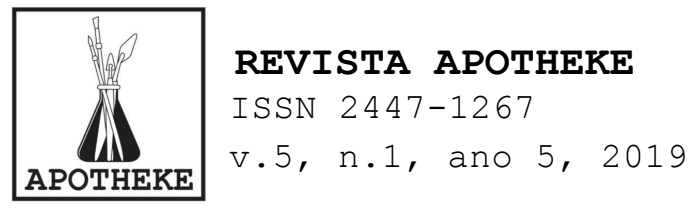

sublinha que "desde o início a peça foi um trabalho total de ficção" (GOLDSMITH, 2010, p. 91, trad. nossa).

\section{$01 \mathrm{~h} 00$}

Uma ficção pode ser concreta, ao passar (também) pelo corpo?

Uma ficção pode acontecer através de pontos de intersecção (precisos e imprecisos) com a realidade?

\section{$22 \mathrm{~h} 19$}

O que seria essa ficção concreta? Como ela aconteceria? Como percebê-la ou pressenti-la? E como propor uma "ficção concreta"?

Desde o início dos processos do projeto Sofá2, havia um desejo de adentrar a escrita enquanto trabalho de arte e como invenção, fissura-ficção, espécie de "fala errante" que atua como espaço de vertigem e espaçamento (BLANCHOT). Mas tentando fisgar pontos de contato (mesmo que informes) com uma espécie de sala errante - o mundo. Havia um desejo e um fôlego (de mãos e corpo inteirol para praticar processos de escrita e intercambia-los, intersectando-os e editando os textos coletivamente. E a escrita não consistia em algo feito somente com palavras. Havia a escrita enquanto uma espécie de estado ou situação, como os gestos de "antes de escrever", quando uma

\footnotetext{
2 Sofá foi um projeto de publicação experimental coletiva por mim coordenado entre 2003 e 2011 nas atividades da disciplina Oficina Avançada Laboratório de Invenção de Textos, ministrada no currículo dos cursos de Artes Plásticas (entre 2003 e 2011) e que teve participação das turmas de Licenciatura e Bacharelado em Artes Plásticas do Centro de Artes (CEART) da UDESC. Nessa disciplina, investigou-se os usos da palavra em proposições artísticas, tendo como parte do processo o desenvolvimento de uma série de exercícios de escrita e a investigação de processos de escrita propostos por artistas, poetas, escritores, músicos e compositores. As publicações impressas possuíam a tiragem de 43 a 1.500 exemplares, sendo também compostas, nas últimas edições, pela relação entre partes impressas e sonoras. A publicação Sofá teve 11 edições, entre elas: Sophá-entrevista (2011), Sofá duplo ${ }^{2}(2006)$, Sofá caixa (2006), Sofá-instável (2005), Sofá lambe-lambe (2005), Sofá-cotovelo (2005), Sofá inflável (2004), Sofá-cama (2004), Sofá Extra!2 (2003) e Sofá (2003).
} 


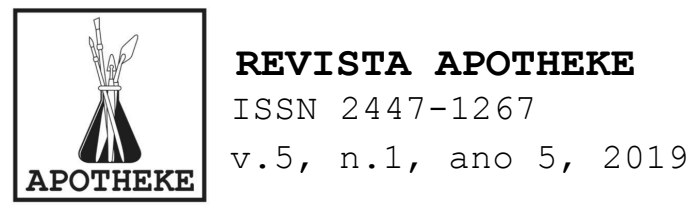

flutuação de coisas acontece, desde acordar com o sonho e a picada de mosquito misturados, até a escrita que nunca deita ou fica parada no papel, a reescrita editada pela boca e pela escuta. A escrita em voz alta, e mesmo a escrita invisível, torta, elétrica, sangrada, esquecida, desfocada, ouvida como um segredo ou como uma conversa aérea.

A ficção concreta passa pelo corpo e por suas experiências de errância (nos pontos de intersecção precisos e imprecisos com a realidade), catalisa perguntas e envolve uma oscilação da/de linguagem.

\section{$07 \mathrm{~h} 33$}

Como a dúvida agarra o pensamento, um projeto, um espaço, um tropeço e move um trajeto? Com o quê estamos às voltas?

\section{$07 \mathrm{~h} 45$}

No FLUXUSFILM 36 (1970) de Peter Kennedy e Mike Parr, só é possível ver o enquadramento retangular da câmera e as pontas de dois pés (sapatos) que percorrem as bordas/limites do quadro, caminhando cautelosamente, sendo guiados por uma voz off (um parceiro ou ajudante invisível), que dá instruções precisas para que ele complete o perímetro, em torno do chão vazio.

\section{$08 \mathrm{~h} 20$}

Em torno de outros espaços, obstáculos e passagens, Kurt Schwitters escreve:

EXPASSOS
ESPAÇOS
ESPAÇOS
ESPAÇOS
UM PASSO
UM
PASSO
FOSSOS
FOSSOS


$09 h 50$

Uma palavra pode ser um buraco, uma passagem?

Uma palavra abre ou fecha um espaço?

Como incorporar, mover e deslocar um registro escrito para/com o corpo e no/com espaço?

\section{$10 \mathrm{~h} 50$}

Como sondar um processo?

\section{$13 \mathrm{~h} 00$}
Como escutar um processo?
Como compor situações de escuta?
Como registrar o quê e como se escuta?

\section{$18 \mathrm{~h} 10$}

A voz e a vez de uma subvoz, quase uma lasca de voz.

Um bocejo. A imersão da boca na voz sem palavras, no instante duplicado (ar duplo) entre dentro e fora do corpo.

\section{$09 h 00$}

Perceber o mar sem a palavra mar.

Tentar compor/decompor um silêncio na escuta.

\section{$10 \mathrm{~h} 52$}

Tentar propor silêncios como tentativas de errância, de estado de não-saber, como experiências inconclusas.

\section{$14 \mathrm{~h} 02$}

Tentar propor um silêncio que atravessa o corpo ou possíveis reverberações de vazios (entre um minuto e outro). 


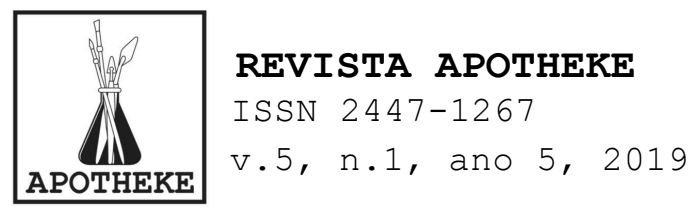

\section{$14 \mathrm{~h} 15$}

Em Demonstration of the Sounds of the Environment (1971), John Cage propôs que trezentas pessoas participassem de uma caminhada em silêncio, determinada ao acaso, pelo campus da Universidade de Wisconsin, em Milwaukee. Seria possível modular silêncios no interstício entre audição (fora/dentro) e escuta (dentro/fora)?

\section{$14 \mathrm{~h} 30$}

Thierry Davila (2002) assinala que a prática do andar participa de um movimento oscilatório que pode relacionar interior e exterior, processo físico e processo intelectual. Para o autor, caminhar constitui uma maneira de fazer um gesto: as práticas do andar possuem uma natureza "cineplástica", pensada como a tentativa de não reduzir o movimento à simples mobilidade física, mas ao contrário, como uma tomada do movimento em toda sua amplidão, em todas as suas maneiras, compreendendo-as em suas "dimensões psíquicas e fantasmáticas" (DAVILA, 2002, p. 27, trad. nossa).

\section{$15 \mathrm{~h} 40$}

Sair da sala: propor caminhadas até um bambuzal e/ou de pés descalços, na areia da praia, sob o rumor do mar, a partir de PEÇA DE CAMINHADA (1964), de Yoko Ono, com e sem abafadores de ruídos ${ }^{3}$.

\footnotetext{
3 Venho me apropriando e utilizando abafadores de ruídos (equipamentos de proteção auditiva em forma de fone, que reduzem o volume/intensidade do som ambiente) em uma série de ações e proposições, bem como, em exercícios de escrita e escuta em oficinas, aulas e cursos (como Laboratórios de escuta e escrita). Na oficina Laboratório Imersivo - Projeto TUBO DE ENSAIO, houve a proposição de caminhadas com/sem abafadores, com exercícios de escrita/escuta no SESC-Cacupé (Florianópolis-SC) e seus bambuzais, e também em seus arredores, como na praia em frente ao SESC, a partir de $P E C ̧ A D E$ CAMINHADA de Yoko Ono. Sobre a proposição Abafador de ruídos: http://www.raquelstolf.com/?p=2604 e http://www.raquelstolf.com/?p=4577. Acesso em 04/02/2019.
} 


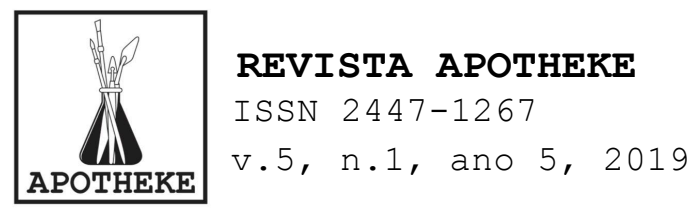

$17 \mathrm{~h} 00$

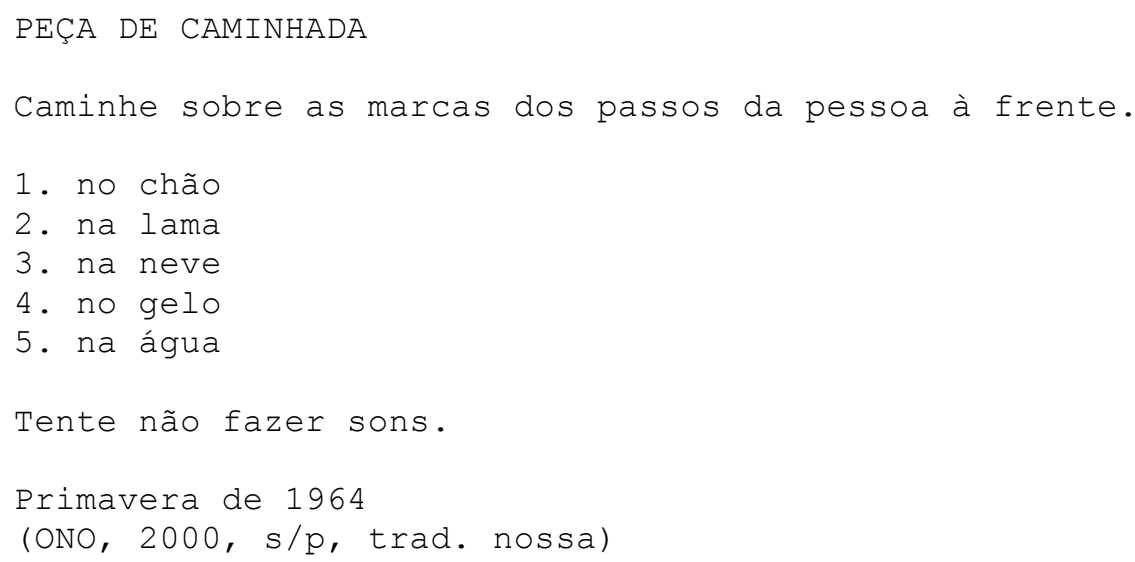

Em Grapefruit: A Book of Instruction and Drawings (2000) ${ }^{4}$, Yoko Ono apresenta uma série de partituras textuais que, como aponta Hans Ulrich Obrist (2009), em entrevista com a artista, constituem obras ilimitadas em duração, ou como ela mesmo assinala, uma "obra inacabada" devido a sua constituição propositiva. Algumas das partituras de Grapefruit propõem também experiências, percepções, imaginações e sensações acústicas de sonoridades silenciosas, inaudíveis, entre outras experiências, como a escuta do som da neve caindo, do som da água subterrânea, ou ainda:

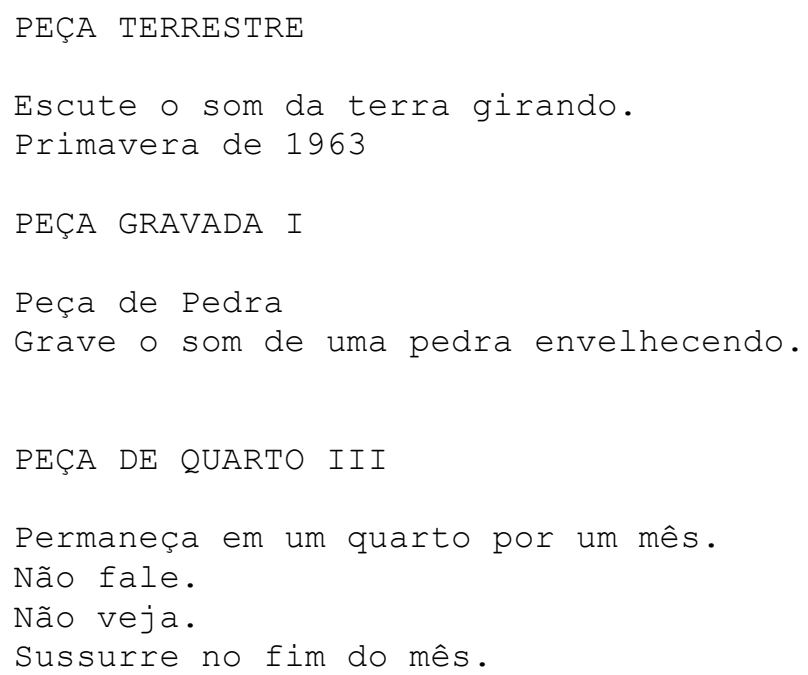

4 Grapefruit foi publicado primeiramente numa edição de 500 exemplares, pela Wunternaum Press, em Tóquio, em 1964. Em 1970, Ono agrega às instruções iniciais outras peças e desenhos produzidos nos anos seguintes. 


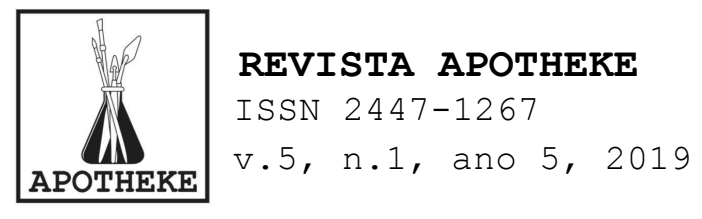

Inverno de 1963

(ONO, 2000, s/p, trad. nossa)

\section{$22 \mathrm{~h} 00$}

Se há espécies de silêncios (entre o envelhecimento de uma pedra e alguém que se cala, entre silere e tacere) ${ }^{5}$ há também relações heterogêneas entre experiências de silêncio e experiências de vazio. David Le Breton (1999) sublinha que o silêncio não é um resíduo ou um vazio a preencher, mas ele pode nos desbastar, de modo que voltemos a ficar disponíveis, "arrumando o espaço" em que nos debatemos. O autor lembra que "A palavra tem mesmo mais dificuldade de passar sem o silêncio do que o inverso [e ao mesmo tempo,] não existe palavra sem silêncio" (LE BRETON, 1999, p. 17). Há uma dimensão de intimidade e de exterioridade do silêncio: "O silêncio nunca é uma realidade em si, mas uma relação, uma condição humana, no interior de uma relação com o mundo." (1999, p. 143). E se para John Cage (1978), o silêncio envolve a possibilidade de começarmos a ouvir/escutar o entorno, possibilitando perceber também o rumor ou o balbucio de nossa escuta, há como ensaiar um silêncio fora de sua ocorrência e experiência?

\section{Referências}

BARTHES, Roland. O neutro: anotações de aula e seminários ministrados no Colliège de France, 1977-1978. (apresentação por Thomas Clerc). São Paulo: Martins Fontes, 2003.

\footnotetext{
5 Roland Barthes, em O Neutro, aponta que etimologicamente, a palavra silêncio carrega duas nuances que se opõem, mas ao mesmo tempo, coexistem: tacere (um silêncio verbal) e silere (uma espécie de ausência de ruído e de movimento, uma quase tranquilidade). Tacere remete ao silêncio de alguém que não fala, sendo um silêncio em relação às palavras. Já silere refere-se aos objetos para além de seus nomes, ao mar, à noite, ao vento ou ao ovo ainda não chocado. Envolve um estado intemporal das coisas, um antes de nascer ou o depois de desaparecer. Em minha pesquisa de doutorado, intitulada Entre a palavra pênsil e a escuta porosa [investigações sob proposições sonoras], desenvolvida no Programa de Pós-Graduação em Artes Visuais da UFRGS, com orientação de Hélio Fervenza, investiguei diferentes percepções, experiências e conceitos de silêncio, no bloco Silêncio acústico. Para ler-ver-escutar a pesquisa: http://www.raquelstolf.com/wpcontent/uploads/2000/09/TESE RaquelStolf 20111.pdf. Acesso em 02/02/2019.
} 


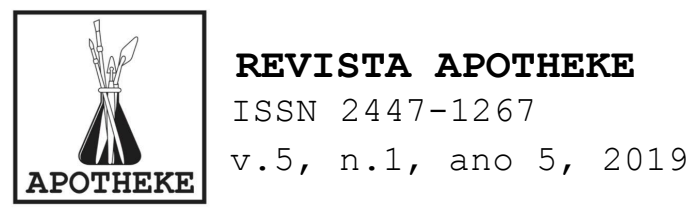

BLANCHOT, Maurice. A Conversa Infinita: a palavra plural. São Paulo: Escuta, 2001 .

- O espaço literário. Rio de Janeiro: Rocco, 1987.

BRECHT, George. Eventos (notas reunidas), 1961. In: o que é Fluxus? o que não é! O porquê. Rio de Janeiro, Brasilia: Centro Cultural Banco do Brasil, Detroit: The Gilbert \& Lila Silverman Fluxus Collection Foundation, 2002.

BOSSEUR, Dominique; BOSSEUR, Jean-Yves. Revoluções musicais: a música contemporânea depois de 1945. Lisboa: Editorial Caminho, 1990.

CAGE, John. John Cage: Dois toques para o Brasil (entrevista). In: Código 3. Salvador, agosto 1978 .

DAVILA, Thierry. Marcher, Créer: Déplacements, flâneries, derives dans lárt de fin du $X^{e}$ siècle. Paris: Éditions du Regard, 2002.

GoLdSMith, Kenneth. Fidget. Toronto: Coach House Books, 2010.

GOLDSMITH, Kenneth apud PERLOFF, Marjorie. "VOCABEL SCRIPTSIGNS": Differential Poetics in Kenneth Goldsmith's Fidget. In: GOLDSMITH, Kenneth. Fidget. Toronto: Coach House Books, 2010.

LARROSA, Jorge. Tremores: escritos sobre a experiência. Belo Horizonte: Autêntica Editora, 2014.

- La experiencia de la lectura: estudios sobre literatura y formación. Barcelona: Laertes, 2003.

LE BRETON, David. Do Silêncio. Lisboa: Instituto Piaget, 1999.

NANCY, Jean-Luc. À escuta. Belo Horizonte: Edições Chão da Feira, 2014.

ONO, Yoko. Grapefruit: A Book of Instruction and Drawings. New York: Simon \& Schuster, 2000 .

- (Entrevista). In: OBRIST, Hans Ulrich. Entrevistas: volume 1. Rio de Janeiro, Belo Horizonte: Cobogó, Inhotim, 2009, p. 31-52.

SCHWITTERS, Kurt. Beingrenzen. In: CAMPOS, Augusto de. Irmãos germanos. Florianópolis: Editora Nôa Nôa, 1992, s/p.

SICHEL, Berta; FRANK, Peter (orgs.). Fluxus y Fluxfilms: 1962-2002. Madrid: Museo Nacional Centro de Arte Reina Sofía, 2002.

STOLF, Maria Raquel da Silva. Entre a palavra pênsil e a escuta porosa [investigações sob proposições sonoras]. Tese (Doutorado em Artes Visuais). Instituto de Artes, Universidade Federal do Rio Grande do Sul, Porto Alegre, 2011. (com CD de áudio).

- Perguntas, anotações [sob exercícios de escrita e escuta] In: MEYER, Sandra; XAVIER, Jussara; TORRES, Vera (orgs.). Tubo de ensaio: composição [Interseções + Intervenções]. Florianópolis: Instituto Meyer Filho, 2016, $\mathrm{v} .1, \mathrm{p} .21-30$. 


REVISTA APOTHEKE
ISSN 2447-1267
APOTHEKE
v.5, n.1, ano 5, 2019

\section{Raquel Stolf}

Currículo Lattes: http://lattes.cnpq.br/5013920052280092

Artista e professora nos cursos de Graduação e Pós-Graduação em Artes Visuais da UDESC. Licenciada em Artes Plásticas (UDESC), com Mestrado e Doutorado em Artes Visuais (UFRGS). Vem desenvolvendo a pesquisa Processos de escrita / Escuta de processos [articulações entre voz, palavra e silêncio em publicações sonoras] (2015-2021) e coordena o selo céu da boca desde 2006, editando publicações como: anecoica (2014, 2015, 2016; com a ed. Nave), Mar paradoxo (2013-2016), Troca de sabonetes (2013), Assonâncias de silêncios [coleção] (2007-2010), Sofá duplo² (2006). Co-editou a Revista Recibo 33 com ruído, com Traplev (2012) e a publicação PLUVIAL FLUVIAL, com Claudia Zimmer (2013). Publicou trabalhos em: Entre ser um e ser mil: o objeto livro e suas poéticas (org. Edith Derdyk, 2013), Cadernos de desenho (org. Aline Dias, 2010) e Ciranda (org. Paulo Silveira, 2005). 